\title{
REMARKS ON HEREDITY IN RELATION TO TUBERCULOSIS *
}

BY

G. GREGORY KAYNE, M.D., M.R.C.P.(LoND.).

The literature on the relation of heredity to tuberculosis is extensive. An attempt will be made here to deal with the main arguments, particularly those of the more recent work in France. For a comprehensive survey of the subject at the end of the last century the reader is referred to Küss ${ }^{20}$.

The relation of heredity to tuberculosis must be considered in two aspects: (a) inheritance of seed, (b) inheritance of soil. By the former is meant the transmission from the parent to the child of tubercle bacilli or other biological variety of the virus. This may show itself (1) as ' evident congenital tuberculosis ', when fully developed lesions are found in the foetus or infant at birth-a term preferable to that of 'prenatal tuberculosis' used by Whitman and Greene $^{33}$, as the latter includes also merely the demonstration of tubercle bacilli in the placenta or organs of the foetus or infant; or (2) as ' congenital latent tuberculosis,' the possibility of which was first suggested by Baumgarten ${ }^{2}$. He considered that some tubercle bacilli were transmitted to the infant, in whom they lay dormant for a while, but eventually produced tuberculous disease. The delay in the development of the lesions he attributed to inherited resistance from the mother. Landouzy ${ }^{21}$, on the other hand, suggested that the latent interval might be due to the small number of bacilli. When referring to the transmission of tubercle bacilli only the mother is generally considered, but it has been suggested by Baumgarten ${ }^{2}$ that this might also occur through the male sperm. The description of a filterable form of the tubercle virus $\left(\right.$ Fcntès $^{14}$, Vaudremer ${ }^{32}$, Valtis ${ }^{31}$ ), and the reported demonstration of its passage from a pregnant guinea-pig to the foetus (Calmette, Valtis, Nègre, and Boquet ${ }^{6}$ ) introduces a further possibility as regards the transmission of the ' seed' both from the mother and the father.

Inheritance of soil includes the possibility of transmission of toxins and antibodies from the mother to the foetus, generally considered under this heading. [This classification is perhaps not accurate, although both these substances might influence the growth of tubercle bacilli acquired after birth.] Also to be considered is the inheritance of certain cellular

\footnotetext{
* Part of a report on work done while holding a Dorothy Temple Cross Research
} Fellowship in Tuberculosis awarded by the Medical Research Counci]. 
characteristics or a 'diathesis.' The following effects have been stated to result from these factors: a. various constitutional effects, such as stillbirths, congenital deformities, ' tuberculous type,' and many other conditions (Landouzy ${ }^{21}$ and Mosny $^{24}$ ); and b. a predisposition to the development of tuberculous disease, the organisms having been acquired after birth (Hutinel ${ }^{18}$, Diehl and v. Verschuer ${ }^{12}$, Ickert and Benze ${ }^{19}$ ).

\section{Evident congenital tuberculosis.}

The occurrence of tuberculous lesions in the newly-born infant is known as a rare phenomenon. The infant is either premature, still-born or dies shortly after birth. In the last case it may be difficult to exclude the possibility of post-natal contagion unless the infant has been rigidly separated from the mother immediately after birth (see Couverlaire and Lacomme ${ }^{8}$ ). Whitman and Greene ${ }^{33}$ reported a case of evident congenital tuberculosis and reviewed the literature on the subject. Couvelaire and Lacomme ${ }^{8}$ found one example in a successive series of $\mathbf{5 0 0}$ tuberculous women who.were confined in the special department of the Baudelocque Maternity, although it is to be noted that only 66 of the 116 infants who died in the first three months died at Beaudelocque (the diagnosis in the remaining 50 is not stated); in another case the possibility of post-natal contact could not be excluded. Lelong ${ }^{22}$ describes evident congenital tuberculosis as presenting three types of pathological picture. The main feature in all is that the lesions are not predominantly pulmonary. On the other hand, Habitz $^{16}$ reported a case of ' congenital tuberculous infection with certainty' dying at three weeks, the same day as the mother, and at the post-mortem examination disseminated tubercles were found in both lungs of the infant. For fuller details and references on the subject of evident congenital tuberculosis reference should be made to the papers of Whitman and Greene $^{33}$, Debré and Lelong ${ }^{10}$, and particularly Siegel ${ }^{30}$.

\section{Mechanism of transmission of the tubercle virus.}

Clinical observation as shown by the occurrence of evident congenital tuberculosis has thus established that the transmission of the organisms of tuberculosis may occur. The view that tubercle bacilli may be transmitted by the spermatozoa or the ovum has not received much support. The presence of tubercle bacilli in either of these germinal cells has never been satisfactorily demonstrated and it seems probable that an ovum so infected would not be likely to mature. Friedmann ${ }^{15}$ has described animal experiments suggesting the possibility of such transmission. The filterable form of tubercle virus appears to offer a further possibility in this direction. The amniotic fluid is not likely to play the sole part in the transmission. 
A rare phenomenon may be the passage of tubercle bacilli to the placenta as the result of extension from tuberculous lesions of the genital tract of the mother. Transplacental transmission seems the most likely mechanism. It is of interest to mention the observation of Debré and Lelong ${ }^{10}$ that all published cases of evident congenital tuberculosis are concerned with foetuses more than four months old, the period when the placental circulation is established. It is probable, however, that earlier foetuses are rarely obtained and examined.

Work along various lines tends to support the theory of transplacental transmission of the tubercle virus.

(1) The presence of tubercle bacilli in the blood of tuberculous patients under certain conditions has of recent years been demonstrated.

(2) Tuberculosis of the placenta has been described. Debré and Lelong $^{10}$ quote the work of Schmorl, Lehmann and Sitzenfrey. While admitting the rarity of microscopic lesions in the placenta these German authors insist on the frequency of such lesions in tuberculous women (Schmorl 45 per cent., Lehmann 45 per cent., Sitzenfrey 27 per cent.). These lesions may occur as extension of uterine tuberculosis but most commonly as the result of spread through the blood. They are rare in chronic pulmonary tuberculosis. Debré and Lelong ${ }^{10}$ themselves examined the Jacenta of twenty-eight tuberculous women. No macroscopic lesions were onscovered in any of them, and guinea-pig inoculations remained negative. It may be asked, whether or not a healthy placenta allows the passage of tubercle bacilli. Debré and Lelong $^{10}$ quote evidence that maternal white blood corpuscles may pass into the placenta. It may therefore be assumed that tubercle bacilli could be carried by these cells or passed through on their own, ' the fact that the bacilli are present in the placenta is not necessarily proof of their reaching the foetus.' Debré and Lelong injected into guineapigs 5 c.c. of the blood from the umbilical cord of the babies of ten tuberculous women. All the results were negative.

(3) The filterable form of the tubercle virus (ultra-virus tuberculeux) was first described by Fontès ${ }^{14}$, of Rio de Janeiro, in 1910. His discovery was at first discredited but observations similar to his were made by Vaudremer ${ }^{32}$ in France in 1922. The subject was then further investigated by Valtis $^{31}$ and bacteriologists in several countries. The organism is described as a Chamberland filter-passer, non-acid-fast, capable after repeated animal passages of giving rise to an acid-fast bacillary form. Calmette, Valtis, Nègre and Boquet ${ }^{6}$ demonstrated the passage of this filterable virus from pregnant guinea-pigs to the foetus. Calmette, Couvelaire, Valtis, and Lacomme in the experiments described below demonstrated the presence of the filterable virus in the organs of the foetuses or infants dying soon after birth. It must be stated that considerable doubt is widelv expressed as 
regards the existence of this virus. It is felt that the results are due to the passage of a few bacilli of little virulence through the filter.

(4) The presence of tubercle bacilli in infants dying from general causes. Debré and Lelong ${ }^{10}$ performed careful necropsies with aseptic precautions on fifteen infants born of tuberculous mothers (all of whom had bacilli in the sputum but varied in the degree of severity of their disease-from ' most benign forms to very severe, several dying soon after the confinement '). These infants were born dead or died soon after birth from unknown causes. Histological examinations and guinea-pig inoculations from numerous organs and placentas were carried out with negative results. On the other hand, Couvelaire and Lacomme ${ }^{8}$, with the help of Calmette, performed experiments along similar lines with the organs of twenty-six foetuses and infants still born or dying soon after birth from tuberculous mothers suffering chiefly from advanced disease, and found in twenty infants either typical tubercle bacilli or a filter-passer. For fuller details of these experiments and discussion of results see Calmette and Valtis ${ }^{5}$. (See also the conclusions of Couvelaire and Lacomme $^{8}$ on the result of these and other experiments with the filterable virus.)

\section{Inheritance of soil.}

Transmission of toxins. Debré and Lelong ${ }^{10}$ examined the organs, and particularly the liver and spleen, of still-born infants or those separated from their mother at birth, for histological changes suggesting toxic lesions. Their results were negative. Similarly Couvelaire and Lacomme ${ }^{8}$ mention that in their experiments with twenty-six foetuses and infants already quoted no evidence of any toxins could be discovered in the filtrates of the organs.

Transmission of antibodies. The transmission of antibodies from mother to foetus is known to occur in relation to diphtheria and measles. In regard to tuberculosis, antibodies were first demonstrated in the human foetus by Parisot and Hanns ${ }^{26}$ using the Bordet-Gengou complement-reaction, and later by Rosencranz ${ }^{29}$. The work of Ribadau-Dumas, Cuel, and Prieur ${ }^{28}$, Cooke $^{7}$, and Debré and Lelong ${ }^{10}$ shows that (1) the passage of antibodies for tuberculosis from mother to infant via the placenta is a definite and frequent phenomenon; (2) that it is not simple filtration, for the placenta seems to take an active part in concentrating or activating them; and (3) that the antibodies rapidly and spontaneously disappear in eight to ten weeks.

Clinical observations on 500 tuberculous mothers. The observations of Couvelaire and Lacomme ${ }^{8}$ on a consecutive series of 500 confinements at a special department for tuberculous women at the Baudelocque Clinic were made under unique conditions and their findings will be briefly summarized. The women were observed over the period 1921-1927. In almost all the cases bacilli were present in the sputum. In the remainder the diagnosis was confirmed by a competent physician. A few suffered from non-pulmonary tuberculosis. All infants born alive were separated from the mothers immediately at birth, and stayed at the hospital on an average from one to two months. Afterwards they were in most cases separated, being either brought up by relatives away from the mother or else sent to 'L'Oeuvre du Placement Familial des Tout-Petits,' an association which boards out these 
infants and home-contacts with healthy families in the country under medical and nursing supervision. It will be referred to subsequently as the 'P.F.T.P.' No abnormal intrauterine development was noted. There were eleven abortions. With weight as a criterion, prematurity was relatively infrequent. The weight of the infants at birth was in the majority of cases under the average of new-born in the hospital class. Death of the foetus in utero with retention and maceration was observed in only three cases. The appearance of all the other infants at birth was normal. Malformations were rare. Thirty-four were still-born; these include infants dying in the first three days, according to the custom of official statistics in France. (In France a delay of three days is allowed in registering a birth. An infant who was therefore not registered and died within that period may be notified as stillborn.)

The relation between physical state of new-born and tuberculosis of mother is of interest. In regard to malformations, these were too few for the relation to have any value. A direct relation was however found between the severity of the mother's illness and the abortions and weight of the infant at birth.

TABLE 1.

Of 51 mothers who aborted or

gave birth to infants under $2000 \mathrm{gm}$. 33 or $64 \cdot 7$ per cent. died within three months

Of 62 mothers who gave birth

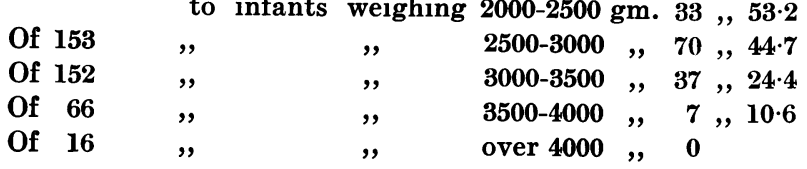

\begin{tabular}{|c|c|c|c|}
\hline ", & , & , & , \\
\hline , & , & ," & , \\
\hline ,' & , & ," & , \\
\hline ,' & , & ", & ," \\
\hline ," & , & " & ," \\
\hline
\end{tabular}

This direct relation does not necessarily imply a specific relation; the explanation may merely be that the tuberculous toxaemia causes prematurity as in any acute illness or infection.

The authors' conclusions on the total deaths (up to three days of life and including abortions) from the 500 women are as follows:-The total of fifty deaths (it is difficult to see how this figure is arrived at as eleven abortions and thirty-four still-births make a total of forty-five only), includes eight syphilitics, four due to obstetrical trauma and two abortions definitely not due to tuberculosis, leaving a total of thirty-six foetuses and new-born infants whose death might be attributed or indirectly to tuberculosis, giving an 'initial mortality' of $7 \cdot 2$ per cent.

There were 450 living infants from the 500 tuberculous women. Most of them stayed at Baudelocque a few weeks, many three months and some more than four months. Amongst them 116 or 25.7 per cent. died before the age of three months (61 died in the first month). Of these, 66 died at Baudelocque (this number includes two who died in the fourth month); forty-six of them were premature or weighed less than $3,000 \mathrm{gm}$.

The causes of death are divided into (a) infections (pulmonary, otitis, influenza, erysipelas), 41 ; (b) various causes such as strangulated hernia, convulsions, etc., 8; (c) tuberculosis, 2 (see page 158); and (d) progressive malnutrition, 15. Three-quarters of (a) and (b) are attributed to crossinfection (as shown by the fact that groups of death occur periodically) and to artificial feeding. Improving the hygienic conditions of the wards by prompt isolation of sick infants and introducing human milk fo feeding 
caused an immediate drop in this mortality. The term progressive malnutrition is applied to a group of infants who, weighing slightly less than average at birth, continued to lose weight after the normal initial fall and died at the end of the first to the third week without clinical or post-mortem signs of any lesion. These deaths occurred even when the infants were fed on human milk. A similar syndrome was found amongst infants of mothers suffering from other severe illnesses, but more rarely. The syndrome has apparently no relation to the gravity of the tuberculous disease in the mother. Moreover, this mortality diminishes as the conditions of the rearing of the infants improved. Thus there were ten deaths in the first series of 209 and five deaths in the second series of 241 , but it does not disappear entirely. Lelong ${ }^{22}$ considered that it was due entirely to the artificial conditions of upbringing, but Couvelaire and Lacomme did not find this syndrome amongst infants of healthy mothers under similar conditions. They attributed it to the tuberculosis of the mother. The successive drop in the mortality of the infants from tuberculous mothers at Baudelocque is shown in the follows:-Third day to third month, 116; third to sixth month, 30; sixth from third day; see page 161).

TABLE 2.

\begin{tabular}{ccc|c|c|c}
\hline \multicolumn{2}{r|}{ Year. } & & No. of cases. & Deaths. & Mortality per cent. \\
\hline $1921-23$ & $\ldots$ & $\ldots$ & 57 & 19 & 33 \\
$1923-25$ & $\ldots$ & $\ldots$ & 151 & 20 & $13 \cdot 2$ \\
$1925-26$ & $\ldots$ & $\ldots$ & 111 & 8 & $7 \cdot 2$ \\
$1926-27$ & $\ldots$ & $\ldots$ & 131 & 14 & $10 \cdot 7$ \\
\hline
\end{tabular}

The progress at Baudelocque of most of the infants who survived was that of normal infants. In some there was a difficulty with feeding, the gain in weight at first being irregular. A third group behaved at first like the group described under progressive malnutrition, then suddenly without change of diet, they began to put on weight, as if they had 'overcome something.'

Later mortality. Of the surviving 450 infants 184 were dead at the age of three years (mortality 40 per cent.). These deaths were distributed as follows :- Third day to third month, 116; third to sixth months, 30; sixth month to a year, 26 ; one to two years, 9; two to three years, 3 . Of 112 infants taken away by the relatives 24 died before three months and 44 later, giving a total mortality of 60 per cent. up to three years. Of the 184 deaths, 66 occurred at Baudelocque-64 before three months, and 43 at the P.F.T.P. -13 before three months (it is stated that none of the latter died of tuberculosis). This leaves a total of 75 deaths out of 184 (40 per cent.) which occurred in the family or in other hospitals. Of the 116 who died under three months 66 per cent. had been under observation either at Baudelocque or at the P.F.T.P. The diagnosis in the 75 infants whose death occurred outside these two institutions is not stated. 
The main criticism of the paper by Couvelaire and Lacomme is that nothing is said with regard to the infants who died in the first three months elsewhere than at the Baudelocque Clinic and the P.F.T.P. The argument that as ' most of these infants had often been in more or less prolonged contact with their tuberculous mothers' which ' would suffice to remove all interest from the diagnosis even if it could be known,' does not disprove that some of them were possibly examples of evident congenital tuberculosis. Similarly nothing is said with regard to the cause of death of the older children who did not die at the P.F.T.P. In these again it is not known in what rôle contact played and they might include examples of congenital latent tuberculosis.

Whilst the investigation is thus incomplete, nevertheless the occurrence of only one case of evident congenital tuberculosis and of no case of tuberculosis up to three years in the children under observation (more than half of the total number, and not a picked sample) tends to support the conclusions of Couvelaire and Lacomme which are as follows:-(1) (Evident) congenital tuberculosis is exceptional. (2) Latent congenital tuberculosis does not show itself at any rate up to the age of three years in infants separated at birth. (3) The large infantile mortality in the first few months is chiefly due to the artificial upbringing, but a specific factor cannot be excluded.

\section{Discussion.}

The results obtained by separating infants and children from tuberculous parents as carried out by the existing associations in France need not be considered here, for, as will be shown below, they can neither prove nor disprove the possibility of latent congenital tuberculosis or of 'inheritance of the soil.' From the evidence submitted in this paper it seems impossible to form any definite conclusions as to the rôle of heredity in the causation of tuberculosis.

In discussing the ' inheritance of the seed' of tuberculosis it is essential in the first place to distinguish sharply between children born of tuberculous fathers and those born of tuberculous mothers. It is extremely unlikely that transmission of organisms from the male occurs, unless the existence of the filterable form of the virus be definitely admitted. That transmission of bacilli from the mother occurs not infrequently seems probable. The existence of cases of evident congenital tuberculosis presupposes the possibility of the passage of small number of bacilli with a delay in the appearance of tuberculous disease. This is further supported by the finding of tubercle bacilli in still-born infants or in those dying shortly after birth after having been rigidly separated from their mothers. Moreover the filterable virus may play a rôle in view of the experiments quoted. 
Unfortunately there is no investigation giving the causes of deaths of all the infants dying within even three months of separation from a large series of tuberculous mothers.

It might be argued that those infants who are most likely to inherit tubercle bacilli from their mothers would be born of women with advanced disease and acutely ill, and therefore would generally be under-weight and debilitated infants, likely to die in the first few days of their existence, before the tubercle bacilli have had time to produce definite lesions. The surviving infants would therefore (a) be less likely to have inherited bacilli and in any case in fewer numbers, (b) would be stronger, and (c) possibly be able to deal with the few bacilli by means of the antibodies which have been shown to exist in the infant in the first few weeks of life. The absence of tuberculosis in 217 infants separated at birth and brought up in a tuberculosis-free environment in the country by the P.F.T.P. may therefore be accounted for by selection, that is, they represent survivals who are not likely to have inherited any bacilli, or be due to the prevention of the development of tuberculous disease as a result of the improvement in the hygienic conditions. The latter reason has been brought forward by Lumière $^{23}$, a strong partisan of the theory of heredity.

In relation to the last argument it is essential to consider the question of tuberculin tests in the infants, separated at birth and brought up by the P.F.T.P., who did not have 'BCG' (as the latter produces a positive tuberculin reaction after a varying interval). Bernard ${ }^{3}$ states that with Debré he investigated the Pirquet test in 300 children from the P.F.T.P., separated from family contagion at birth or before infection has taken place (that is, they were Pirquet-negative on their admission) and 'placed in country homes absolutely free from tuberculosis.' Those children were excluded in whom the delay of the appearance of the reaction seemed too short to enable them ' to state definitely that the previous family contact, which had been interrupted, could not be incriminated.' Only five developed a positive Pirquet test during their stay in the country; in one of these contact had possibly taken place, but in the four others no contact whatever could be ascertained (three of these infants had been separated at birth).

A little later, however, Bernard, Debré, and Lelong ${ }^{4}$ state ' en effet chez les enfants séparés dès la naissance et que nous avons longuement suivi dans les mêmes centres d'élevage, s'ils n'ont pas reçu de BCG, jamais la cuti-réaction ne s'est montrée positive.' Again, referring to the same children Debré and Corfino ${ }^{9}$ state that these children maintain a negative Pirquet reaction till their departure (at four years) except in a few exceptional instances, where they have been able in each case to find visits of tuberculous parents and contacts. They state that of 151 such children they examined with the Mantoux test (up to a dilution of 1 in 200) all were negative. Debré, Lelong, and Pictet ${ }^{11}$ tested eighty children (who had been separated at birth) with the Mantoux test up to a dilution of 1 in 10-all were negative; but amongst 134 children who had been in contact some time before separation, but were Pirquet-negative on admission (those who became positive soon 
after admission are not included in this group, but are assumed to have been contaminated), twenty-one gave a feebly positive or doubtful reaction. It should be stated that contrary to the opinion expressed by Hart ${ }^{17}$ that the frequent occurrence of false reactions with this dilution necessitated the use of a control test, these authors had not employed the latter in their investigation.

According to Léon Beinard's original statement one must assume that the environment of these children in the country is not ' absolutely' free from tuberculosis; otherwise one is faced with the conclusion that the three children separated at birth who developed a positive Pirquet test may be cases of congenital latent tuberculous infection. It is of interest to note that of these three children one had a tuberculous father and the reaction became positive at the age of three-and-a-half years, and in the other two the mother was tuberculous, the test becoming positive at the age of one year and of two-years-and-eight months respectively. The long latent interval does not necessarily exclude such a possibility for the following reasons. (a) It is considered by some authors that a period even up to four months (ante-allergic period) may elapse between the time of contact and the appearance of a positive tuberculin test. (This is not admitted by every worker, Wallgren (private communication), for example, considers the maximum as eight weeks.) It is possible that when tubercle bacilli are inherited, because of the small number in these surviving infants and because of the inherited immune bodies, such a latent period may be more prolonged. (b) The Pirquet test is admitted not to be very sensitive, and it is possible that if a Mantoux test in a strong dilution had been used these three infants would have been found to react positively at a much earlier age. (c) The association between the filterable form of the tubercle virus and the state of allergy is not yet understood. A recent paper by Paisseau, Valtis and van Deinse ${ }^{25}$ describes positive skin tests obtained with a tuberculin derived from the filterable virus in the absence of a positive test with ordinary tuberculin. It must be concluded that even at the estimate of three positive Pirquet reactions in an environment assumed absolutely tuberculosis-free, the presence of latent congenital tuberculous infection is rare.

If it is assumed that the transmission of bacilli from the mother to the infant may rarely show itself as a positive tuberculin test after an interval of a year or more, must the appearance of tuberculous disease in these children be expected after a short interval? This is not necessarily so. It is considered by many authorities that pulmonary tuberculosis in the adult is at any rate in many individuals the result of endogenous reinfection from tuberculosis acquired in childhood, that is, there exists a latent period of some years. It is reasonable to assume that such a prolonged latent period may occur between the appearance of a positive tuberculin test due to inherited bacilli and that of manifest disease, which may thus show itself only in adolescence. Only the fate of a large number of children separated from all tuberculous contact since birth and followed up to adolescence could 
decide this point and it might well be asked whether an absolutely tuberculosis-free atmosphere could easily be obtained for this length of time. The statistics offered by the P.F.T.P. do not help, for this association only has existed since 1920, keeps children only till the age of four years, and, in any case, soon after its foundation it became the practice to vaccinate the children with BCG. Similarly, the results of the Oeuvre Grancher, although founded in 1903, are useless, as (a) until 1920 only children from the age of three years were admitted, most of whom are already infected and picked as regards their good health, (b) the Great War interfered with the followingup of those under the care of the association before 1914, (c) no adequate follow-up department exists at present, and (d) a large proportion of the children are taken out by their parents after only a short stay.

Inheritance of the soil may be regarded as a diathesis favourable to the development of the tubercle bacillus and transmitted along Mendelian lines. So that while heredity would not determine infection, it would in some individuals (children or adults) determine the development of disease once infection has been acquired as the result of contact after birth. Karl Pearson $^{27}$ after statistical analysis of 383 patients in whom the family history was exhaustively studied states ' the diathesis of pulmonary tuberculosis is certainly inherited, and the intensity of the inheritance is sensibly the same as that of any normal physical characteristic, for example, stature, span, cubit, eye-colour, etc., yet investigated in man. A theory of infection does not account for the facts.'

The most serious contribution to this subject of recent years is the work of Diehl and v. Verschuer ${ }^{12}$ who elaborately examined (including the family history and environment) 126 pairs of twins in 106 of whom at least one of the pair had some tuberculous manifestation. They found that whereas ' tuberculosis concordance' was present in 70 per cent. of the uniovular twins it was only present in 25 per cent. of the binovular. They conclude that a hereditary specific predisposition (i.e. involving morphological and immunological characters) exists, and that its influence becomes more marked with age. Ickert and Benze ${ }^{19}$ after analysis of the genealogical trees of eighty-eight families reach the same conclusion and suggest that it is transmitted as a recessive character. On the other hand, Drolet ${ }^{13}$ found that adult consumptives born of tuberculous parents resisted the disease better. His work has, however, been severely criticized.

The follow-up department of the P.F.T.P. has not yet been able to collect evidence to indicate whether such a diathesis may play a part in determining tuberculous disease in home-contacts already infected. But a considerable number of the children admitted with a positive Pirquet test and separated, after careful observation to insure that they are not clinically tuberculous at the time of admission, developed tuberculous disease later. With regard to the Oeuvre Grancher, Armand-Delille ${ }^{1}$ gives the following 
figures : 4,000 children admitted since 1907, twelve cases of tuberculosis, with three deaths; but it must be remembered that by far the larger proportion of children leave after a short stay only and it is not known what happened to them.

\section{Conclusions.}

(1) The transmission of tubercle bacilli from mother to foetus occurs not infrequently, as shown by cases of evident congenital tuberculosis and the presence of tubercle bacilli in infants separated from their tuberculous mothers from birth and dying of other causes.

(2) Infants with inherited tubercle bacilli probably die in the first few days or weeks of life of (apparently) non-tuberculous causes.

(3) There is no evidence that heredity plays any rôle in the causation of the large incidence of tuberculous infection found amongst home-contacts.

(4) Heredity does not appear to be responsible for the occurrence of tuberculous disease in the children of tuberculous parents at any rate in their first few years of life, provided post-natal contact has been avoided.

(5) Inheritance of a diathesis or a ' specific predisposition' may determine the occurrence of tuberculous disease and its prognosis, both in children and adults, once post-natal infection has taken place.

\section{REFERENCES}

1. Armand-Delille, P. F., Paris méd., Paris, 1933, XXIII, 1.

2. Baumgarten, P., Klin. Vorträge, No. 218 (Inn. Med. 1882, No. 74, 1955).

3. Bernard, L., Am. Rev. Tuberc., New York, 1927, XV, 169.

4. Bernard, L., Debré, R., \& Lelong, M., Bull. Acad. de méd., Paris, 1928, C, 1021.

5. Calmette, A., \& Valtis, J., Ann. Inst. Pasteur., Paris, 1930, XLIV, 629.

6. Calmette, A., Valtis, J., Nègre, L., \& Boquet, A., Compt. rend. Acad. d. Sc., Paris, 1925, CLXXXI, 491.

7. Cooke, J. V., Am. Rev. Tuberc., New York, 1922, VI, 127.

8. Couvelaire, A., \& Lacomme, M., Médecine, Paris, 1931, XII, No. 3 (Suppl.).

9. Debré, R., \& Corfino, E., Bull. Soc. de pédiat. de Paris, Paris, 1929, XXVII, 301.

10. Debré, R., \& Lelong, M., Ann. de méd., Paris, 1925, XVII, 209, 601.

11. Debré, R., Lelong, M., \& Pictet, Ann. Inst. Pasteur, Paris, 1932, XLIX, 4.

12. Diehl, K., \& v. Verschuer, O. F., Zwillingstuberkulose, Jena, 1933.

13. Drolet, G. J., Amer. Rev. Tuberc., New York, 1924, X, 280.

14. Fontès, A., Quoted by Valtis, J. (see ref. 31).

15. Friedmann, F., Virchows Arch. f. path. Anat., Berlin, 1905, CLXXXI, 150.

16. Habitz, F., Am. J. Dis. Child., Chicago, 1927, XXXIII, 458.

17. Hart, P. D'A., Med. Res. Council Spec. Rep. Series, No. 164, London, 1932.

18. Hutinel, Semaine méd., Paris, 1889, IX, 229. 
19. Ickert, F., \& Benze, H., Stammbaüme mit Tuberkulösen, Leipzig, 1933.

20. Küss, A., Thèse de Paris, 1898.

21. Landouzy, L., Rev. de méd., Paris, 1891, XI, 411.

22. Lelong, M., Thèse de Paris, 1925.

23. Lumière, A., Tuberculose, Contagion, Hérédité, second edition, Lyon, 1931.

24. Mosny, E., Rev. de la Tuberc., Paris, 1901, VIII, 301 and 407.

25. Paisseau, G., Valtis, J., \& van Deinse, F., Presse méd., Paris, 1934, XLII, 185.

26. Parisot, J., \& Hanns, Rev. méd. de l'est, Nancy, 1910, XLII, 236.

27. Pearson, K., quoted by Struthers, J. A., Tubercle, Lond., 1930, XI, 99.

28. Ribadeau-Dumas, L., Ceul, \& Prieur, Rev. de la tuberc., Paris, 1921, II, 378.

29. Rosencranz, E., Compt. rend. Soc. de biol., Paris, 1911, LXIII, 142.

30. Siegel, M., Am. Rev. Tuberc., New York, 1934, XXIX, 297.

31. Valtis, J., Ann. Inst. Pasteur, Paris, 1924, XXXVIII, 453.

32. Vaudremer, A., Médecine, Paris, 1922, III, 622.

33. Whitman, R. C., \& Greene, W. L., Arch. Int. Med., Chicago, 1922, XXIX, 261. 